\title{
A educação, o poder da ideologia e a escola sem partido ${ }^{1}$
}

\author{
Fabiane Santana Previtali \\ Cílson César Fagiani
}

\begin{abstract}
Resumo: O objetivo deste artigo é problematizar as complexas relações entre o mundo do trabalho e a educação num contexto histórico determinado pela dialética articulação entre as condições objetivas da produção material e as formas da consciência social que se manifestam na superestrutura ideológica, político-jurídica a fim de demonstrar que a proposta do movimento político "Escola Sem Partido", surgido em 2004, de interromper o avanço daquilo que o movimento denomina como contaminação político-ideológica nas escolas brasileiras, da educação básica ao ensino superior nada mais é que ela mesma, uma ideologia.
\end{abstract}

Palavras-chave: Escola sem partido. Educação. Ideologia.

\section{Education, the power of ideology and the school without a party}

\begin{abstract}
The objective of this article is to problematize the complex relations between the world of work and education in a historical context determined by the dialectical articulation between the objective conditions of material production and the forms of social consciousness that are manifested in the ideological, political-juridical superstructure in order to demonstrate that the proposal of the political movement "School Without a Party", which emerged in 2004, to interrupt the advance of what the movement calls political-ideological contamination in Brazilian schools, from basic education to higher education is nothing more than an ideology.
\end{abstract}

Keywords: School without a party. Education. Ideology.

\footnotetext{
${ }^{1} \mathrm{CNPq}$ e Fapemig.
} 


\section{Introdução}

Lombardi (2014), ao problematizar a educação nos escritos de Marx e Engels, destaca que, para eles, a educação está inserida no contexto histórico em que surge e se desenvolve, sendo fruto dos movimentos contraditórios que emergem do processo das lutas de classe. Para o autor, Marx e Engels “[...] trataram a educação como uma dimensão da vida dos homens que se transforma historicamente, acompanhando e articulando-se às transformações dos modos de produzir a existência dos homens" (p. 11).

A educação é um instrumento formador e de expressividade sociocultural e não pode - e nem deve - ser vista dentro de limites fechados, analisada independentemente e de forma apartada da sociedade. Portanto, a educação não se pauta pela neutralidade. No âmbito desse movimento histórico e dialético, Mészáros (2008, p. 50) irá afirmar que a educação:

[...] ao mesmo tempo que se constitui como elemento fundamental para a produção das condições objetivas de manutenção da ordem social do capital, é também meio para a construção de uma estratégia para uma outra forma de sociabilidade, que esteja para além do capital.

Assim, a educação materializada na escola é resultado de uma construção histórica erigida a partir e na dinâmica das lutas entre as classes sociais. Nos momentos de crise do capitalismo, quando se abrem fissuras nos blocos hegemônicos de poder, as classes trabalhadoras e os movimentos sociais reivindicam uma educação fundada em princípios libertários e socialistas. Mas, no momento seguinte, a burguesia, ao reconstruir-se politicamente, impõe novamente - e com grande intensidade - o seu projeto de dominação e a educação volta a ter essencialmente um caráter eminentemente classista que circunscreve os anseios da classe trabalhadora às determinações da reprodução do capitalismo. Desse modo, as mudanças na educação, por mais bem-intencionadas que possam parecer ser, não passam de reformas pontuais e não colocam em causa as determinações da lógica vigente.

Há, dessa forma, uma intencionalidade quanto aos objetivos educacionais societais que se consubstanciam em políticas educacionais. Estas por sua vez, se traduzem em projetos educacionais desenvolvidos nas escolas e que têm como alvo direto os profissionais da educação e os estudantes e, de uma maneira mais geral, a sociedade. A escola almeja determinar a construção de uma moral de obediência, de disciplina e de conformação que visa à reprodução do 
PREVITALI, Fabiane Santana; FAGIANI, Cílson César. A educação, o poder da ideologia e a escola sem partido.

sistema societal. Para Mészáros (2008, p. 35), “a educação institucionalizada serve ao propósito de não só fornecer os conhecimentos e o pessoal necessário à máquina produtiva em expansão do sistema capital, como também gerar e transmitir um quadro de valores que legitima os interesses dominantes", bem como inviabilizam as tentativas de oposição a eles.

Entretanto, na dinâmica do movimento socio-histórico, o domínio pretendido pela instituição escolar na construção da obediência não ocorre sem resistências e lutas, quer sejam no âmbito das reivindicações político-legais na esfera parlamentar, quer sejam no cotidiano do ambiente escolar. Um exemplo que merece ser ressaltado diz respeito à experiência dos estudantes do ensino médio que ocuparam as escolas por quase todo o Brasil, em 2016. Depois das manifestações nas ruas em 2013-2014, os jovens estudantes ocuparam as escolas públicas pela defesa da educação básica. Um processo de organização e luta pelo ensino público se processou e impactou fortemente não apenas esses jovens diretamente envolvidos, mas as gerações futuras. Deve-se atentar ao caráter histórico desse amplo movimento pois representou a retomada da construção coletiva de um projeto de participação e de controle social pelos próprios sujeitos sociais da escola, em particular os estudantes do ensino médio.

O movimento coletivo iniciado pelos estudantes por si só já foi bem-sucedido posto que superou o individualismo ultra-exacerbado e destrutivo - mas reinante -, referência fundamental para a reprodução da ideologia burguesa sob o neoliberalismo e trouxe à tona a primazia dos interesses coletivos. Foi um movimento que colocou em xeque a onda conservadora que se formou nos últimos anos no Brasil - e no mundo - em que predomina, como diz Antunes (2015), "o negociado sobre o legislado".

Esses jovens de 15 a 17 anos nada tiveram de ingênuos. Ao contrário, foram conscientes e assumiram a enorme responsabilidade de pensar e lutar pela educação básica pública. Diversamente do que prevalece no imaginário do senso comum, de que os estudantes não se interessam pela escola, eles afirmaram o desejo de participar nas decisões que influenciam diretamente sua formação e das gerações futuras. Tomaram o destino em suas mãos ao invés de aceitar acriticamente o autoritarismo das medidas governamentais.

Aos poucos, uma rede de pequenos coletivos estudantis do ensino público, em sua maioria jovens da classe trabalhadora em seus extratos mais precarizados, com seu destino já traçado, 
PREVITALI, Fabiane Santana; FAGIANI, Cílson César. A educação, o poder da ideologia e a escola sem partido.

como força de trabalho superexplorada ${ }^{2}$, ocupante dos piores postos de trabalho no mercado, com alta rotatividade, menor qualificação e baixa remuneração, foi se constituindo por todo o país. E passaram a negar esse destino já traçado não por Deus, mas pela burguesia nacional e internacional, articuladas na esfera do Estado para o desmonte da educação pública.

O movimento Escola Sem Partido está inserido nesse contexto. Criado em 2004, um ano após o início do governo Lula (2003-2011), ele retroage às iniciativas desses estudantes pertencentes à classe-que-vive-do-trabalho, que contou com o apoio de pais e de professores. Se o movimento de ocupação estudantil impunha o debate ideológico e político na escola quanto à sua função social, o movimento Escola Sem Partido, ao contrário, busca despolitizá-la em nome da "neutralidade científica" e assim conservá-la em seu papel fundamental, qual seja: de reprodução da dominação burguesa. Para Frigotto (2017), num contexto de avanço da organização da classe trabalhadora e dos movimentos sociais, ao mesmo tempo em que se acentuava a crise econômica mundial, a estratégia da classe dominante brasileira foi lançar mão das ideologias mais reacionárias e conservadoras a fim de garantir seus lucros e privilégios.

Para tanto, a Escola Sem Partido estabelece um manual de conduta dirigido especialmente aos trabalhadores docentes a fim de promover o que chama, em sua página oficial, de a “descontaminação e desmonopolização política e ideológica das escolas” (ESCOLA SEM PARTIDO, 2017).

Mas, como é possível apartar a educação da política e afirmar uma escola sem ideologia e neutra? Ensina-se na escola que o indivíduo deve ser o mais competitivo possível e obter qualificações técnicas que atentam ao mercado de trabalho. Não é isso uma ideologia? Como afirma Mészáros (2011), a ideologia é uma forma específica de consciência social que se sustenta materialmente. Ela está presente nas diversas sociedades, desde a antiguidade até o presente. Como forma especifica de consciência social, ela é inseparável das sociedades de classe.

\section{Ideologia e educação}

Para Mészáros (2011), a ideologia é parte de um sistema vital de representações e ideias

\footnotetext{
${ }^{2} \mathrm{O}$ conceito de superexploração do trabalho diz respeito à uma combinação da mais-valia absoluta com a mais-valia relativa por meio da intensificação na exploração da força de trabalho. Ele foi elaborado por Ruy Mauro Marini nos anos 1960 e 1970.
} 
PREVITALI, Fabiane Santana; FAGIANI, Cílson César. A educação, o poder da ideologia e a escola sem partido.

que surge e repousa sobre uma base material, as condições materiais de produção, mas, simultaneamente, se impõe à base material numa relação dialética que se funda na correspondência e na reciprocidade entre infraestrutura e superestrutura. A ideologia não pode ser eliminada por um conhecimento alicerçado neutralidade científica porque a própria ciência traz em si a ideologia. Na medida em que o conhecimento científico está alicerçado numa relação social que se funda na propriedade privada, a ciência e também a tecnologia, embora produzidas socialmente são, em última instância, determinadas por interesses privados. Não são os sujeitos sociais produtores que definem qual ciência, qual tecnologia, enfim, qual conhecimento será desenvolvido, mas sim, o proprietário capitalista. O conhecimento científico sob a lógica do capital é uma mercadoria que deverá, essencialmente, servir à valorização do capital e não à satisfação das necessidades humanas. Nesse aspecto é esclarecedora a argumentação de Antunes (2000, p. 122) para quem é preciso ter-se em conta que o desenvolvimento da ciência e da tecnologia é determinado pela lógica de acumulação do capital e não pelas necessidades humanas, pois, "ao mesmo tempo em que a ciência é liberada pelo capital para expandir-se ela é, em última instância, subordinada aos imperativos do processo de criação de valores de troca”.

A maneira pela qual a burguesia, enquanto classe dominante, mistifica a apropriação e a exploração da força de trabalho alheia, aliena o sujeito de seus meios de produção, de seu trabalho e de si mesmo, submetendo-o às piores condições de vida para a produção da mercadoria está vinculada ao "poder da ideologia" (MÉSZÁROS, 1996). É a ideologia dominante que mantém e fortalece os interesses das classes dominantes pela via da ilusão, da criação de valores e comportamentos que levam o indivíduo a ignorar a sua realidade concreta como resultado de um conjunto de determinações constituído histórica e socialmente a partir das relações sociais de produção e reprodução da vida. Segundo Mészáros (1996, p. 14):

\footnotetext{
Nas sociedades capitalistas liberal-conservadoras do ocidente, o discurso ideológico domina a tal ponto a determinação de todos os valores que muito frequentemente não temos a mais leve suspeita de sermos levados a aceitar, absolutamente sem questionamento, um determinado conjunto de valores a que se poderia opor uma perspectiva alternativa muito bem fundamentada, juntamente com as consequências práticas que nele se encontram mais ou menos implícitas. [...] Aqueles que aceitam tacitamente a ideologia dominante como estrutura objetiva do discurso 'racional' e do 'erudito' rejeitam como ilegítimas todas as tentativas de identificar as suposições ocultas e os valores implícitos com que está comprometida a ordem dominante. Assim, em nome da 'objetividade' e da 'ciência' têm de desqualificar o uso de algumas categorias essenciais do pensamento crítico.
} 
PREVITALI, Fabiane Santana; FAGIANI, Cílson César. A educação, o poder da ideologia e a escola sem partido.

Portanto, as ideias e os valores que se supõe verdadeiros são cotidianamente veiculados pela mídia e sistematicamente ensinados pelas instituições sociais como as igrejas, as escolas, as universidades, na tentativa de criar uma consciência consensual, de que tudo é como deve ser. No capitalismo, o fundamento específico sob o qual se produz a riqueza é o trabalho alienado, o trabalho não pago, imposto pelo capital sob a aparência de ser trabalho "livre"3 e disposto no mercado para ser vendido e comprado uma relação entre iguais. É no sentido de ocultar essa relação social de exploração, fundamento da sociabilidade sob o capital que se erige a ideologia burguesa. Nas palavras de Marx e Engels (2007, p. 93-94):

A produção de ideias, de representações e da consciência está em primeiro lugar diretamente entrelaçada à atividade material e as relações materiais dos homens, com a linguagem da vida real. As representações, o pensamento, o comércio intelectual dos homens surge aqui como emanação direta do seu comportamento material. O mesmo acontece com a produção intelectual quando esta se apresenta na linguagem das leis, política, moral, religião, metafísica, etc., de um povo. São os homens que produzem as suas representações, de suas ideias e assim por diante, mas os homens reais, atuantes e tais como foram condicionados por um determinado desenvolvimento das suas forças produtivas e do modo de relações que lhe corresponde, incluindo até as formas mais amplas que estas possam tomar. A consciência não pode ser jamais outra coisa do que o ser consciente e a existência dos homens é o seu processo da vida real. E se em todas as ideologias os homens e as suas relações nos surgem invertidos, tal como acontece numa câmara obscura, esse fenómeno resulta tanto do seu processo vital histórico, quanto a inversão dos objetos na retina de seu processo vital físico.

É nesse sentido que Marx e Engels (2007) irão afirmar que as relações legais, as formas de Estado, a religião, a linguagem, a educação, constituem a superestrutura da sociedade e não podem ser entendidas por si mesmas, mas, ao contrário, estão arraigadas às condições materiais da vida.

Para Altrusser (1980), nas sociedades capitalistas avançadas, a materialização da ideologia se dá principalmente na instituição escolar ${ }^{4}$. Nesse sentido, a escola assume a tarefa de inculcar nas crianças de todas as classes sociais durante anos de audiência obrigatória os saberes, não apenas relacionados à qualificação técnicas, mas também àqueles concernentes às regras morais de boa convivência social. Todos estão envolvidos no processo de produção e reprodução do sistema, mesmo aqueles que chegam no topo da pirâmide escolar e principalmente estes, que

\footnotetext{
${ }^{3}$ Indica-se livre entre aspas porque entende-se que o termo traz em si uma mistificação ideológica. Na verdade, os trabalhadores são constrangidos a vender sua força de trabalho sob as condições impostas pelo capital sob o risco de não sobreviverem. Em épocas de crise de acumulação do capital, tal qual vivencia-se atualmente esses constrangimentos tornam-se ainda mais imperativos.
}

${ }^{4}$ Para o autor, a escola constitui um dos aparelhos ideológicos do Estado.

Quaestio, Sorocaba, SP, v. 20, n. 3, p. 583-599, dez. 2018 
PREVITALI, Fabiane Santana; FAGIANI, Cílson César. A educação, o poder da ideologia e a escola sem partido.

vão ocupar postos de agentes da exploração, no sistema produtivo, postos de agentes da repressão, nos aparelhos repressivos, e postos de profissionais da ideologia nos aparelhos ideológicos. Para Altrusser (1980, p. 20-22):

Ora, o que se aprende na Escola? Vai-se mais ou menos longe nos estudos, mas de
qualquer maneira, aprende-se a ler, a escrever, a contar, - portanto algumas técnicas, e
ainda muito mais coisas, inclusive elementos (que podem ser rudimentares ou pelo
contrário aprofundados) de 'cultura científica' ou 'literária' diretamente utilizáveis nos
diferentes lugares da produção (uma instrução para os operários, outra para os técnicos,
uma terceira para os engenheiros, uma outra para os quadros superiores, etc. Aprendem-
se, portanto 'saberes práticos'. -Mas, por outro lado, e ao mesmo tempo que ensina estas,
técnicas e estes conhecimentos, a Escola ensina também as regras dos bons costumes,
isto é, o bom comportamento que todo o agente da divisão do trabalho deve observar,
segundo o lugar que está destinado a ocupar: regras da moral, da consciência cívica e
profissional, o que significa exatamente regras de respeito pela divisão social-técnica do
trabalho, pelas regras da ordem estabelecida pela dominação de classe. Ensina também o
bem falar, a redigir bem, o que significa exaltadamente (para os futuros capitalistas e
para os seus servidores) a 'mandar bem', isto é, (solução ideal) a falar bem aos
operários, etc. Enunciando este fato numa linguagem mais cientifica, diremos que a
reprodução da forca de trabalho exige não só uma reprodução da qualificação desta, mas,
ao mesmo tempo, uma reprodução da submissão desta às regras da ordem estabelecida,
isto é, uma reprodução da submissão desta à ideologia dominante para os operários e
uma reprodução da capacidade para manejar bem a ideologia dominante para os agentes
da exploração e da repressão.

Assim, uma vez que os profissionais da educação são formados pelo próprio sistema educacional em que irão atuar, a possibilidade de desenvolverem a crítica e, mais ainda, autocritica é bastante remota. Na forma particular de sociabilidade burguesa, os sujeitos sociais são reduzidos a trabalhadores "livres" posto que somente possuem sua força de trabalho para vender ao capital em troca do salário. O capitalista, por sua vez, irá dispor dessa força de trabalho como qualquer outra mercadoria, isto é, enquanto for útil para reprodução do valor.

No campo da batalha das ideias como espaço de luta de classe, a educação institucionalizada serve ao propósito, mais geral, de construir a obediência. Desse modo, a natureza da educação no capitalismo está determinada pela forma como o trabalho está edificado, qual seja: trabalho alienado, explorado, abstraído de sua concretude para ser apenas meio de vida daquele que cria a riqueza social.

\section{O Trabalho Alienado e a Natureza Alienante da Educação Burguesa}

O trabalho é uma atividade exclusivamente humana, meio de relação Ser HumanoNatureza. Ele é um elemento de mediação no processo de produção e reprodução de sua 
PREVITALI, Fabiane Santana; FAGIANI, Cílson César. A educação, o poder da ideologia e a escola sem partido.

existência sociocultural na medida em que para satisfazer suas necessidades vitais, age sobre o meio transformando-o e transformando a si mesmo. Nesse processo cria coisas úteis, atribui significado as coisas e cria cultura. Diz Marx (2013, p. 255):

O trabalho é antes de tudo um processo entre o homem e a natureza, processo em que o homem, por sua própria ação, medeia, regula e controla seu metabolismo com a natureza. [...] A fim de apropriar-se da matéria natural de uma forma útil para sua própria vida, ele põe em movimento as forças naturais pertencentes a sua corporeidade: braços, pernas, cabeça e mãos. Agindo sobre a natureza externa e modificando-a por meio desse movimento, ele modifica, ao mesmo tempo, sua própria natureza.

É no momento em que o ser social interage com a Natureza, alterando-a para a satisfação de suas necessidades essenciais e alterando concomitante sua própria natureza, que esses sujeitos entram em relação uns com os outros, ou seja, instituem relações sociais de produção (PREVITALI, 2009). A partir das relações sociais no ato de produção do real se formam todos os subsequentes arranjos superestruturais do ser social em sociedade. Estes, por sua vez, irão também influir na base material, numa relação de determinação a partir da base material, mas, também, de inter-relação determinada, na medida em que a superestrutura alcançará relativa autonomia para influir na base material com vistas a garantir a reprodução ampliada do sistema do capital (MÉSZÁROS, 2011).

Mészáros (2011) chama a atenção para a necessidade de se apreender o significado da relação entre superestrutura e a base material numa complexidade dialética. Não é suficiente, segundo o autor, estipular uma reciprocidade sem considerar o necessário suporte materialista. Não há, dessa forma, uma determinação recíproca, mas uma inter-relação dinâmica a partir da materialidade das relações sociais de produção. Sendo assim, é a partir das determinações materiais de produção e, consequentemente, da divisão social do trabalho que elas engendram, que são erigidas a estrutura social e as suas formas de consciência.

A estrutura social em classes pressupõe interesses divergentes e conflitantes posto que os sujeitos necessitam satisfazer suas necessidades naturais, seja pela exploração do trabalho alheio ou do seu por outrem. O antagonismo de classes advém da necessidade básica humana de produzir e reproduzir suas condições materiais de existência sob condições sociais determinadas, de conflito e contradições determinadas ao longo de um processo histórico.

A separação entre classes antagônicas e fundada na exploração do trabalho para a produção e reprodução do valor se baseia na propriedade ou não dos meios de produção, que, por 
PREVITALI, Fabiane Santana; FAGIANI, Cílson César. A educação, o poder da ideologia e a escola sem partido.

sua vez, funda-se no trabalho alienado (MÉSZÁROS, 2006). O trabalho, enquanto atividade essencialmente humana e criadora, torna-se, ao longo de um processo histórico, trabalho alienado e estranhado na medida em que se torna determinado e forçado por outro, o proprietário dos meios de trabalho. Nas palavras de Marx (2008, p. 82-83):

[...] ser o trabalho externo ao trabalhador, não fazer parte de sua natureza e, por conseguinte, ele não se realizar em seu trabalho mas negar a si mesmo, ter um sentimento de sofrimento em vez de bem-estar, não desenvolver-se livremente em suas energias mentais e físicas mas ficar fisicamente exausto e mentalmente deprimido. $\mathrm{O}$ trabalhador só se sente à vontade em seu tempo de folga quando no trabalho se sente contrafeito. Seu trabalho não é voluntário, porém imposto, é trabalho forçado. Ele não é a satisfação de uma necessidade, mas apenas um meio para satisfazer outras necessidades (grifos do autor).

Ou seja, ocorre uma radical separação entre os produtores diretos - trabalhadores que nada possuem a não ser sua força de trabalho a qual deverá ser vendida como uma mercadoria - e os proprietários dos meios de produção. A partir desse momento, os trabalhadores encontram-se numa relação de subordinação com os proprietários privados que detêm o controle dos meios de produção e da existência dos trabalhadores. Nesse sentido, a alienação não é uma abstração teórico-conceitual, mas uma manifestação concreta que ocorre a partir da divisão do trabalho, quando o produto do trabalho deixa de pertencer a quem o produziu. Dessa forma, a propriedade privada é consequência, resultado da alienação e, ao mesmo tempo, meio pelo qual o trabalho é alienado. Ela carrega consigo o pressuposto que torna possível a legitimidade social da apropriação privada do trabalho alheio. É nesse sentido que Marx (2008, p. 82) irá afirmar:

Por certo o trabalho humano produz maravilhas para os ricos mas produz privação para o trabalhador. Ele produz palácios, porém choupanas é o que toca ao trabalhador. Ele produz beleza, porém para o trabalhador só fealdade. Ele substitui o trabalho humano por máquinas, mas atira alguns trabalhadores a um gênero bárbaro de trabalho e converte outros em máquinas. Ele produz inteligência, porém também estupidez e cretinice para os trabalhadores.

Do que foi acima exposto decorre-se que a divisão dos homens em classes sob o signo do trabalho alienado irá engendrar também uma divisão também na educação.

Para Saviani (2007), a origem do ser social ${ }^{5}$ está estreitamente vinculada a um processo educativo posto que, este ser, ao agir sobre a natureza transformando-a em função de suas próprias necessidades adquire um conhecimento, realiza um aprendizado o qual é transmitido às

\footnotetext{
${ }^{5}$ Optou-se neste artigo, utilizar a categoria "ser social" ao invés de Homem. 
PREVITALI, Fabiane Santana; FAGIANI, Cílson César. A educação, o poder da ideologia e a escola sem partido.

gerações futuras. Isso significa que o homem não nasce homem. Ele forma-se ser social na medida em que o ato de trabalhar e também um ato de aprender e ensinar. Nas palavras do autor:

Se a existência humana não é garantida pela natureza, não é uma dádiva natural, mas tem de ser produzida pelos próprios homens, sendo, pois, um produto do trabalho, isso significa que o homem não nasce homem. Ele forma-se homem. Ele não nasce sabendo produzir-se como homem. Ele necessita aprender a ser homem, precisa aprender a produzir sua própria existência. Portanto, a produção do homem é, ao mesmo tempo, a formação do homem, isto é, um processo educativo. A origem da educação coincide, então, com a origem do homem mesmo. Diríamos, pois, que no ponto de partida a relação entre trabalho e educação é uma relação de identidade. Os homens aprendiam a produzir sua existência no próprio ato de produzi-la (SAVIANI, 2007, p. 154).

No entanto, ressalta o autor, com o surgimento da sociedade de classes e propriedade privada passam a haver duas modalidades distintas e separadas de educação. De um lado, uma educação uma para a classe proprietária, identificada como a educação dos homens e mulheres livres e, de outro lado, uma educação para a classe não-proprietária, destinada inicialmente aos escravos, aos serviçais e finalmente, na sociedade capitalista burguesa, aos trabalhadores e trabalhadoras livres assalariados e assalariadas.

Portanto, é o modo como se organiza o processo de produção, a maneira como os sujeitos sociais produzem os seus meios de vida, que permitiu a organização da escola como um espaço separado da base material. Em seu processo de gestação a escola não é um simples veículo para a transmissão e circulação das ideias, mas também - e sobretudo - o cenário de uma serie de práticas sociais significativas. Isso denota que as teorias pedagógicas explicativas da realidade são, elas mesmas, produzidas dentro e a partir dessa realidade que, por sua vez, é histórica e dinâmica.

É nesse sentido que Mészáros (2008) afirma serem as propostas educacionais mais ousadas, limitadas em sua base estrutural, quais sejam, as determinações fundamentais do sistema do capital. Para o autor, é necessário que as soluções educacionais não sejam apenas formais, ou seja, meras propostas reformistas, mais essenciais na medida em que abranjam uma práxis de transformação social. Diz ele:

A educação institucionalizada, especialmente nos últimos 150 anos serviu, - no seu todo - ao propósito de não só fornecer os conhecimentos e o pessoal necessário à máquina produtiva em expansão do sistema do capital, como também gerar e transmitir um quadro de valores que legitima os interesses dominantes, como se não pudesse haver nenhuma alternativa à gestão da sociedade, seja na forma 'internalizada' (isto é, pelos indivíduos educados e aceitos) ou através de uma dominação estrutural e uma subordinação hierárquica e implacavelmente impostas (MÉSZÁROS, 2008, p. 35). 
PREVITALI, Fabiane Santana; FAGIANI, Cílson César. A educação, o poder da ideologia e a escola sem partido.

Destarte, os projetos educacionais, assim como as teorias educacionais que os fundamentam têm o seu potencial emancipatório tolhido sob o metabolismo societal do capital, não havendo espaço para a emancipação da humanidade ante o "poder do dinheiro" e da "busca do lucro"6. Segundo Mészáros (2008), pela escola os indivíduos devem ser induzidos a uma aceitação ativa dos princípios reprodutivos orientadores dominantes adequados à sua posição na ordem social e de acordo com as tarefas que lhes foram atribuídas.

Para Saviani (2012), a classe burguesa, detentora do capital e hegemônica na condução da cultura vigente, não tem interesses na transformação da escola, mas, ao contrário, cria as condições ideológicas para reprodução dessa forma de sociabilidade. O autor irá definir as teorias educacionais que julgam ser a sociedade harmoniosa e que têm como objetivo a integração igual de seus integrantes como "Teorias Educacionais não Críticas” e destaca a Pedagogia Tradicional, a Pedagogia Nova e Pedagogia Tecnicista. Nessa vertente, a educação surge como uma força de homogeneização e garantias de inserção social igualitária, sendo vista como autônoma, apartada da sociedade na qual se desenvolve ${ }^{7}$.

Enguita (1989) também tece dura crítica à educação institucionalizada e ao seu caráter alienante que mistifica as concretas relações de exploração da sociedade burguesa sob o falso argumento de não ser ideológica. Para o autor, através das relações sociais e das práticas no interior da escala, crianças e jovens são conduzidos, em termos não apenas cognitivos, mas de atitudes, disposições, normas de conduta, a aceitar as relações sociais do trabalho alienado. A escola se especializa em reproduzir as divisões sociais em divisões escolares sob a falsa aparência da necessidade e da funcionalidade. Ela cria e desenvolve uma aprendizagem que legitima a separação entre trabalho manual e trabalho intelectual e naturaliza as relações sociais de produção da vida social e cultural na e da sociedade burguesa.

\footnotetext{
${ }^{6}$ Grifos do autor.

7 Empenhando-se em analisar sistematicamente as teorias educacionais na educação escolar, Saviani (2012) distinguiu-as em dois grupos fundamentais que se diferenciam principalmente pela maneira como interpretam a relação entre a sociedade e a educação. No primeiro grupo situam-se as teorias que julgam ser a sociedade harmoniosa e que tem como objetivo a integração igual de seus integrantes. A educação surge como uma força de homogeneização e garantias de inserção social igualitária. Neste grupo a educação é vista como autónoma da sociedade na qual se desenvolve. O autor as denomina “Teorias Educacionais não Críticas" e destaca a Pedagogia Tradicional, a Pedagogia Nova e Pedagogia Tecnicista. Não é o propósito deste artigo tecer um debate crítico acerca das teorias educacionais.
}

Quaestio, Sorocaba, SP, v. 20, n. 3, p. 583-599, dez. 2018 
PREVITALI, Fabiane Santana; FAGIANI, Cílson César. A educação, o poder da ideologia e a escola sem partido.

O autor destaca ainda a ideologia do progresso presente na escola segundo a qual a organização social do trabalho capitalista é apresentada como natural, racional ou simplesmente inevitável. Para Enguita (1989), o progresso é apresentado de forma passiva, cujo desenvolvimento é inerente a ele mesmo, independentemente das dinâmicas das relações de classes. Portanto, no nível da neutralidade técnica e a sociedade está fadada a chegar nele com segurança. Ao reiterar cotidianamente, através de suas teorias pedagógicas supostamente neutras, a ideologia do progresso universal, a escola incorpora à sua prática a ideia de progresso individual, sendo este fundado na eficiência e no mérito. Diz Enguita (1989, p. 179):

\begin{abstract}
Naturalmente a escola incorpora com grande a seu discurso ideológico a ideia de progresso: supõe-se que ela própria o personifica e é seu principal instrumento. Mas o que incorpora à sua prática é a ideia de progresso pessoal como algo cumulativo e carente de limites, através da experiência da soma de anos de escolaridade, matérias cursadas, créditos, títulos, etc., e de sua sempiterna insuficiência. Por outro lado, não é difícil associar à escola a convicção de que qualquer tempo futuro será melhor: frente ao cinza do presente escolar, o futuro do trabalho pode parecer pintado com todas as cores do arco-íris e, mesmo que se o anteveja cinza, pelo menos será remunerado.
\end{abstract}

De acordo com o autor, a escola, mesmo pregando nobres ideais como solidariedade, cooperação, trabalho em equipe, estimula a competição e o individualismo entre seus alunos. Ele exemplifica que, a maior parte das vezes quando se fala de um aluno é aplicado, que está sempre disposto a cooperar, significa que esse aluno está resignado a envolver-se nas propostas apresentadas pelo professor, isto é, a obedecer cegamente ao educador da mesma forma que obedecerá futuramente sem questionamentos ao seu patrão. Para Enguita (1989), as instituições escolares, ao apresentarem seus princípios internos, seus critérios de seleção e demais mecanismos como produtos lógicos, científicos e indiscutíveis, acostumam os alunos à ideia de que sua classificação e hierarquização é um fator inevitável. A partir daí os educandos passam a pensar que também são inevitáveis as relações de classe e de salários, o prestígio na sociedade e demais formas de hierarquização social.

De acordo com Baudelot e Establet (1971, apud SAVIANI, 2012) a escola, em que pese a sua aparência unitária e unificadora, está dividida em duas grandes redes, que correspondem à divisão da sociedade capitalista em duas classes fundamentais: a burguesa e o proletariado. Tais redes são denominadas especificamente como rede secundária-superior e rede primáriaprofissional, que atravessam todo o sistema escolar, sendo organizadas desde a escola primária 
PREVITALI, Fabiane Santana; FAGIANI, Cílson César. A educação, o poder da ideologia e a escola sem partido.

até a superior. A rede secundária-superior é destinada a classe burguesa e rede primáriaprofissional é destinada a classe proletária.

Para os autores, mesmo a formação recebida na rede primária-profissional tem função ideológica, quando sujeita o trabalhador à ideologia burguesa sob um disfarce pequeno-burguês qualificando o trabalho intelectual e desqualificando o trabalho manual, impedindo o desenvolvimento da ideologia do proletariado, que tem origem e existência fora da escola, nas massas operárias e em suas organizações.

Também buscando compreender a instituição escolar como um espaço da reprodução da ordem social e da construção dos valores dominantes, Bourdieu e Passeron (2013) argumentaram que o sistema de ensino possui uma "autonomia relativa em relação aos interesses das classes dominantes" (p. 232) que se consubstanciam em práticas ou ações pedagógicas as quais, em última instância, irão servir à perpetuação das relações de classe. Para eles:

\begin{abstract}
A definição de autonomia relativa do sistema de ensino em relação aos interesses das classes dominantes deve sempre levar em conta os serviços específicos que essa autonomia relativa presta à perpetuação das relações de classe: é com efeito à sua aptidão para autonomizar seu funcionamento e obter reconhecimento de sua legitimidade garantindo a representação de sua neutralidade que o sistema escolar deve sua aptidão particular para dissimular a contribuição que ele traz à reprodução da distribuição do capital cultural entre as classes, a dissimulação desse serviço não sendo o menor dos serviços que sua autonomia relativa lhe prestar à conservação da ordem estabelecida (BOURDIEU; PASSERON, 2013, p. 236).
\end{abstract}

Os autores interpretam que as relações de força entre os grupos se fazem presentes na expressão materialista das condições de vida dos sujeitos e que na base e na determinação dessa materialidade tem-se um sistema de relações de força simbólica que reforça, por dissimulação, as relações de força material tendo como base a teoria dos campos. Convém mencionar que a noção de campo em Bourdieu substitui a de sociedade, pois, para ele, uma sociedade não se encontra plenamente integrada por funções sistêmicas, mas, ao contrário, é constituída por um conjunto de microcosmos sociais dotados de autonomia relativa (CATANI, 2011).

Decorre-se desse movimento entre os campos, a violência simbólica, isto é, forma dissimulada em que as relações de força se produzem e reproduzem no reconhecimento da dominação e de sua legitimidade pelo desconhecimento de seu caráter de violência explicita. À violência material, produzida nas relações de produção (dominação econômica) exercida pelos grupos ou classes dominantes sobre os grupos ou classes dominadas corresponde à violência 
PREVITALI, Fabiane Santana; FAGIANI, Cílson César. A educação, o poder da ideologia e a escola sem partido.

simbólica (dominação cultural). Para os autores, além do sistema educacional, essa dominação cultural pode ser estabelecida e difundida por meio das instituições religiosas, atividades artísticas, meios de opinião e de comunicação em massa e educação familiar.

Segundo os autores, a escola exerce um papel fundamental para que os estudantes interiorizem o seu destino, sua posição e suas oportunidades sociais como algo referente apena à sua responsabilidade pessoal. As histórias de vida individuais erigidas sob a base material, assim como os valores e ideias formados a partir de uma realidade concreta dissolvem-se sob a ideologia da igualdade de oportunidades para todos presentes na escola, sendo inculcada cotidianamente, através das práticas pedagógicas, dos conteúdos e das avaliações.

\section{Conclusão}

Conforme exposto ao longo desse artigo, a ideologia está presente na instituição escolar e busca construir no imaginário coletivo uma falsa versão do real. O movimento político Escola Sem Partido, ao se afirmar como apartidário e a-ideológico, traz em si, contraditoriamente, o que há de mais nefasto e reacionário na esfera do pensamento ideológico: a negação da história, do movimento social, da divisão das classes e a defesa, por conseguinte, da naturalização da sociabilidade humana e do pensamento conservador e autoritário. Ele atribui à educação a qualidade de ser, por si só, transformadora. Difunde-se na escola a ideia de uma sociedade aberta e móvel. Nessa vertente ideológica é suficiente estar na escola e ser instruído para alcançar o sucesso. As oportunidades são iguais a todos.

É um movimento que advoga à favor da democracia e liberdades mas nega esses valores à prática cotidiana nas escolas. Professa ideologias. Defende o direito individual mas cerceia o direito dos educadores ensinar em sala de aula, e, por conseguinte, nega ao estudante o direito em aprender a contra-argumentar. Nesse sentido, a Escola Sem Partido almeja, através do controle repressivo à atividade docente, reforçar a ideologia do consenso em torno da obediência e da aceitação quanto às determinações da dominação burguesa, qual seja: o trabalho alienado explorado pelo capital.

Ao mesmo tempo, seus integrantes visam impedir de maneira autoritária que se construa, na escola, uma contraideologia que questione as inabaláveis exigências da ordem burguesa. Assim, a Escola Sem Partido congrega o que há de mais reacionário e conservador no 
PREVITALI, Fabiane Santana; FAGIANI, Cílson César. A educação, o poder da ideologia e a escola sem partido.

pensamento social brasileiro. Aquilo que o movimento quer negar, ou seja, a ideologia, é um fenômeno intrínseco à escola e, portanto, o que o movimento deseja é, fundamentalmente, a negação do debate ideológico no ambiente escolar e, em contrapartida, a imposição dos valores ideológicos dominantes. Nesse sentido, a escola institucionalizada produz ideologia e toma partido: o partido da ordem, alicerçado numa formação unilateral e tecnicista.

O movimento Escola Sem Partido vê os os estudantes como meros depósitos de conteúdos. Não os vê como sujeitos sociais pensantes, mas como indivíduos que devem ser formados unilateralmente, instrumentalizados para ocupar uma posição no mercado de trabalho de acordo com suas qualificações, obtidas de acordo com o seu "esforço", "desempenho" e, portanto, mérito pessoal.

Os estudantes do ensino médio que ocuparam as escolas por todo o país ousaram colocar em causa uma ordem que parecia irreversível e trouxeram à tona o conflito, assustando demasiadamente os setores conservadores da sociedade que se organizaram sob a ideologia mais apedeuta da Escola Sem Partido. Assim, a oposição à Escola Sem Partido significa demonstrar as falsidades presentes em seu discurso e em sua prática. É um discurso que condiz com os valores mais bárbaros da sociedade burguesa, pois assenta-se na defesa do direito individual sem considerar as inter-relações sociais em que o sujeito está inserido.

Importa destacar que a prática educacional deve munir o sujeito para orientar-se no mundo, visando ao esclarecimento de sua consciência num movimento dialético desde a infância. Assim, a educação deve conduzir à emancipação das pessoas, articulada à imaginação e à experiência. Pelo exposto ao longo desse artigo, essa educação não é possível sob a lógica capitalista, que deseja sujeitos abestalhados, obedientes e conformados que responsabilizam a si mesmo pela sua tragédia recorrente.

Isso posto, torna-se fundamental - e urgente como adverte Mészáros - que o conflito ideológico se manifeste na escola de maneira contundente e radical à fím de promover a consciência dos sujeitos sobre si mesmos e sobre o ambiente em que vive, formando-os em uma práxis contrária à submissão, à alienação e à barbárie.

\section{Referências}

ALTRUSSER, L. Ideologia e aparelhos ideológicos do Estado. Lisboa: Presença/Martins Fontes, 1980. 
PREVITALI, Fabiane Santana; FAGIANI, Cílson César. A educação, o poder da ideologia e a escola sem partido.

ANTUNES, R. Os sentidos do trabalho. São Paulo: Boitempo, 2000.

ANTUNES, Ricardo. A sociedade da terceirização total. Revista da ABET, Paraíba, v. 14, n. 1, p. 6-14, jan./jun. 2015. Disponível em: <http://www.periodicos.ufpb.br/ojs/index.php/abet/article/view/25698/ 13874>. Acesso em: 16 ago. 2017.

BOURDIEU, P.; PASSERON, J-C. A reprodução: elementos para uma teoria do sistema de ensino. Petrópolis, Rio de Janeiro: Vozes, 2013.

CATANI, A. M. As possibilidades analíticas da noção de campo social. Educação e Sociedade.

Campinas, v. 32, n. 114, p. 189-202, jan./mar. 2011. Disponível em: <http://www.cedes.unicamp.br>. Acesso em: 12 ago. 2017.

ENGUITA, F. M. A escola oculta: educação e trabalho no capitalismo. Porto Alegre: Artes Médicas. 1989.

ESCOLA SEM PARTIDO. Disponível em: < http://www.escolasempartido.org/objetivos>. Acesso em: 10 out. 2017.

FRIGOTTO, G. (Org.). Escola "sem" partido: esfinge que ameaça a educação e a sociedade brasileira. Rio de Janeiro: UERJ/LPP, 2017.

LOMBARDI, J. C. Modo de produção, transformações do trabalho e educação em Marx e Engels. In: LOMBARDI, J. C. et al. (Org.). Mundialização do trabalho, transição histórica e reformismo educacional. Campinas: Navegando/Histedbr/Unicamp, 2014. p. 11-59.

MARX, K. O Capital: crítica da economia política: processo de produção do capital. São Paulo: Boitempo, 2013. Livro 1.

MARX, K. Manuscritos econômico-filosóficos. São Paulo: Boitempo, 2008.

MARX, K.; ENGELS, F. A ideologia alemã. São Paulo: Boitempo, 2007.

MÉSZÁROS, I. A educação para além do capital. São Paulo: Boitempo, 2008.

MÉSZÁROS, I. Estrutura e formas de consciência: a dialética da estrutura e da história. São Paulo: Boitempo, 2011. v. 2.

MÉSZÁROS, I. O poder da ideologia. São Paulo: Ensaio, 1996.

MÉSZÁROS, I. A teoria da alienação em Marx. São Paulo: Boitempo, 2006.

PREVITALI, F. S. O controle do trabalho pelo discurso da qualificação do trabalhador no contexto da reestruturação produtiva do capital. Humanit. Sci., Appl. Soc. Sci., Linguist., Lett. Arts, Ponta Grossa, v. 17, n. 2, p. 141-155, dez. 2009. Disponível em:

<www.revistas2.uepg.br/index.php/humanas/article/download/1768/1313>. Acesso em: 30 jun. 2017.

SAVIANI, D. Trabalho e educação: fundamentos ontológicos e históricos. Revista Brasileira de Educação, Rio de Janeiro, v. 12, n. 34, p. 152-180, jan./abr. 2007. Disponível em: <www.scielo.br/scielo.php?script=sci_arttext\&pid=S1413-24782007000100012 >. Acesso em: 15 jun. 2017.

SAVIANI, D. Escola e democracia. Campinas: Autores Associados, 2012. 
PREVITALI, Fabiane Santana; FAGIANI, Cílson César. A educação, o poder da ideologia e a escola sem partido.

Fabiane Santana Previtali

Universidade Federal de Uberlândia - UFU | Instituto de Ciências Sociais / Pesquisadora CNPq/PQ e FAPEMIG/PPM

Uberlândia | MG | Brasil. Contato: fabiane.previtali@gmail.com ORCID 0000-0002-8079-5557

Cílson César Fagiani

Universidade de Uberaba - UNIUBE | Programa de Pós-graduação em Educação

Uberlândia | MG | Brasil. Contato: cilsoncf@gmail.com ORCID 0000-0002-2800-8106

Artigo recebido em: 30 mar. 2018 e aprovado em: 16 jul. 2018. 